\section{Involvement of Both Subgroups $A$ and $B$ of Expansin Genes in Kiwifruit Fruit Ripening}

\author{
Shaolan Yang, Changjie Xu, Bo Zhang, Xian Li, and Kunsong Chen ${ }^{1}$ \\ Laboratory of Fruit Molecular Physiology and Biotechnology/The State \\ Agriculture Ministry Laboratory of Horticultural Plant Growth, \\ Development and Biotechnology/Department of Horticulture, Zhejiang \\ University, Huajiachi Campus, Kaixuan Road 258, Hangzhou 310029, P. \\ R. China
}

Additional index words. acetylsalicylic acid, ethylene, expansin, fruit ripening, gene expression, kiwifruit

\begin{abstract}
Two complementary DNA fragments encoding expansin genes $A$ d-EXP1 and $A d-E X P 2$ were isolated from ripening kiwifruit (Actinidia deliciosa cv. Bruno) by reverse transcription-polymerase chain reaction amplification using a pair of degenerate primers. The homology between these two expansin family members was $50 \%$ in nucleotide sequence and $74 \%$ in amino acid sequence. It was revealed that $\mathrm{Ad-EXPI}$ and $A d-E X P 2$ belong to subgroups $A$ and $B$ of an expansin gene family respectively. However, gene expression of these two members shared similar patterns. Both were upregulated by ethylene treatment and downregulated by acetylsalicylic acid treatment. The study suggests that members of both subgroups $A$ and $B$ of the expansin family are involved in kiwifruit fruit ripening.
\end{abstract}

Fruit textural change is one of main processes that occur during fruit ripening and senescence. It affects the postharvest life of fruit as well as fruit quality and commercial value. Softening is a comprehensive result of complex primary cell wall disassembly and the disruption of adhesion between cells. Various enzymes, such as polygalacturonase (Bonghi et al., 1996), pectin esterase (Redgwell and Harker, 1995), cellulase (Gallego and Zarra, 1997), xyloglucan endotransglycosylase (Chen et al., 1999; Redgwell and Fry, 1993), and $\beta$-galactosidase (Redgwell and Harker, 1995; Ross et al., 1993) contributes to degradation of cell wall substance in kiwifruit as well as in other fruits (Bennett, 2002; Cosgrove, 2000; Rose and Bennett, 1999). However, these enzymes might not be the only important factors participating in the disassembly of the cell wall. Antisense inhibition of their expression in some fruit did not greatly retard fruit ripening (Giovannoni et al., 1989; Tieman and Handa, 1994; Tieman et al., 1992; Watson et al., 1994).

Recently, expansin (EXP), a nonenzymatic protein, was found to play an important role in cell wall loosening and extension. Expansin was first discovered while researching the "acid phenomenon" (McQueenMason et al., 1992). It is encoded by a large

Received for publication 30 Aug. 2006. Accepted for publication 24 Nov. 2006.

Supported by the National Natural Science Foundation of China (30571284), the University Doctoral Foundation of China (20040335022), and the 111 project (B06014).

${ }^{1}$ To whom reprint requests should be addressed; e-mail akun@zju.edu.cn

Ad-EXP1 AASDRRSSTSWNIVPANWQFGQTFAGKNFRV

Ad-EXP2 TASDGKTVTSYNVAPGNWQFGQTFEGTQF-

$$
: * \star *:: * *: *: * * * * * \star \star * * * .: *
$$
expansins (EXPs), are in black boxes.
In tomato, $18 E X P$ members have been identified. Le-EXP1 expressed specifically in the ripening fruit (Rose et al., 1997). Its important role in ripening of tomato fruit was noted by Brummell et al. (2002). Overexpression of $L e-E X P 1$ accelerated fruit softening, whereas antisense inhibition of $L e-E X P 1$ retarded it in transgenic tomato. Ripeningrelated members of the expansin family were also identified in peach (Hayama et al., 2000, 2003), strawberry (Harrison et al., 2001), pear (Hiwasa et al., 2003), litchi (Wang et al., 2006a), and banana (Wang et al., 2006b). Expression of ripening-related expansin was induced by ethylene and inhibited by 1-methylcyclopropene, a gaseous ethylene binding inhibitor (Rose et al., 1997, 2000). In addition, salicylic acid (SA), an endogenous plant growth substance regulating plant development and senescence, and its derivative acetylsalicylic acid (ASA) have been reported to inhibit ethylene production in fruit of kiwifruit, pear, banana, and apple (Fan et al., 1998; Leslie and Romani, 1988; Zhang et al., 2003). However, a relation between EXP expression and SA has not been reported. The objective of the current study was to isolate fruit ripening-related $E X P$ members from kiwifruit and evaluate their response to ethylene and ASA.

\section{Materials and Methods}

gene family with members that are extensively involved in plant growth, organ swelling, pollen tube elongation, and fruit ripening (Cosgrove, 2000). Some members express constitutively, whereas others each had individual tissue-specific or/and developmentalspecific expression pattern (Cosgrove et al., 1997; Fleming et al., 1997; Im et al., 2000), although more than one EXP member had been reported to coexpress in a same tissue (Harrison et al., 2001).

Plant material. Kiwifruit (Actinidia deliciosa cv. Bruno) fruit were harvested at commercial maturity with total soluble solids at around $7{ }^{\circ}$ Brix from an orchard at Wuyi, Zhejiang, China. They were transferred to the laboratory on the same day, where fruit of uniform size, maturity, and without disease and mechanical damage were selected and subjected to storage with or without treatments.

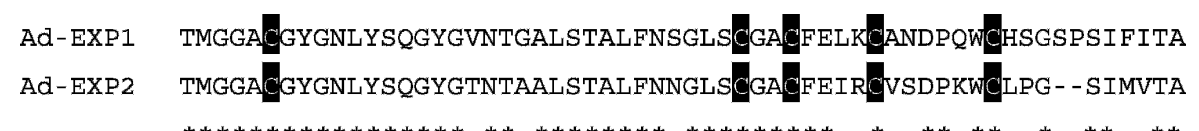

Ad-EXP1 TNFCPPNYALPNDNGGWCNPPRPHFDLAMPMFLKIAEYRAGIVPVSFRRVPCRKQGGIRF Ad-EXP2 TNFCPPNNALPNNAGGWCNPPQHHFDLAQPI FQQIAQYRAGIVPVSYRRVPCLKKGGIRF $* * * * * * * * * * *: * * * * * * *: * * * * * *: *: * *: * * * * * * * * *: * * * * * *: * * * * *$

Ad-EXP1 TINGHRYFNLVLISNVAGAGNIVRVSVKGSRTGWMSMSRNWGQNWQSNAVLVGQSLSFRV Ad-EXP2 TINGHSYFNLVLITNVGGAGDVHAVSIKGSRTGWOPMSRNWGQNWOSNSYLNGQSLSFQV

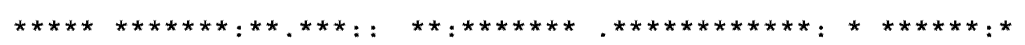

Fig. 1. The deduced amino acid sequences of Ad-EXP1 and Ad-EXP2 fragments. Carboxy-terminal conserved amino acid domains, KNFRV unique to subgroup A and QF to B, are framed. Conserved cystein (C), tryptophan (W) residues, and a His-Phe-Asp (HFD) domain, characterized by plant 
Treatments and sampling. After precooling at $15{ }^{\circ} \mathrm{C}$ for $2 \mathrm{~h}$, the fruit were exposed to ethylene $\left(100 \mu \mathrm{L} \cdot \mathrm{L}^{-1}, 12 \mathrm{~h}\right)$, stored at $20^{\circ} \mathrm{C}$, and sampled at $0,3,6,12,24,72,120$, and $156 \mathrm{~h}$ after treatment. For the last sampling, the fruit were sorted into four groups according to the rate of ethylene production as described later in the text. In another separate experiment, fruit were separated into three groups after precooling at $15^{\circ} \mathrm{C}$ for $2 \mathrm{~h}$ and exposed to ethylene $\left(100 \mu \mathrm{L} \cdot \mathrm{L}^{-1}, 12 \mathrm{~h}\right)$, immersed in ASA ( $1 \mathrm{~mm}$; $\mathrm{pH}, 3.5 ; 5 \mathrm{~min})$, or not treated (control). These fruit were then stored at $20^{\circ} \mathrm{C}$, sampled at $-12 \mathrm{~h}$ (refers to the time point just before treatment), $0,24,48$, $72,96,120,144,168,216$, and $264 \mathrm{~h}$ after treatment. Each sampling consisted of three replicates of 10 sample fruit. After measuring the rate of ethylene production, fruit firmness, and total soluble solids content, the pulp tissue without seeds from a core at an equatorial slice $(\approx 2.5 \mathrm{~cm}$ thick) from each fruit was taken, combined, frozen in liquid nitrogen, and stored at $-70{ }^{\circ} \mathrm{C}$ until analysis.

Analysis methods. Rates of ethylene production, fruit firmness, and total soluble solids were measured as described by Zhang et al. (2003).

Total RNA was extracted according to our previously published protocol (Xu et al., 2004). Degenerate sense primer EXPSP, 5' ACAATGGGNGGDGCDTGTGG-3' (D = $\mathrm{A} / \mathrm{G} / \mathrm{T}, \mathrm{N}=\mathrm{A} / \mathrm{C} / \mathrm{G} / \mathrm{T}$ ) and antisense primer EXPAP, 5'-TGCCARTTYTGNCCCCAR TT-3' $(\mathrm{R}=\mathrm{A} / \mathrm{G}, \mathrm{Y}=\mathrm{T} / \mathrm{C})$ were designed according to the conserved regions of plant expansin sequences deposited in GenBank with accession numbers AF038815, AF096776, AF297527, AB093029, and AB029083. Reverse transcription and polymerase chain reaction (PCR) amplification was performed according to $\mathrm{Xu}$ et al. (2004) with an annealing temperature of $50^{\circ} \mathrm{C}$. The $3^{\prime}$ end of the fragment was amplified with a 3' RACE kit (Takara, Dalian, China) according to the instructions of the supplier. The reaction products were analyzed on $1.0 \%$ agarose gel containing $0.5 \mu \mathrm{g} \cdot \mathrm{mL}^{-1}$ ethidium bromide. The PCR products were cloned into pUCm-T (Shanghai Sangon, Shanghai, China) according to Sambrook and Russell (2001). Sequencing was completed by Shanghai Sangon. The sequences were aligned with Clustal X 1.81 (Institut de Genetiave et de Biologie Moleculaire et cellvlaire (CNRS/INSERM/VLP), Illkirch Cedex, France) and BioEdit 5.0.9, (Toln Hall, Ibis Therapeutics, Carlsbad, Calif.) and phylogenetic analysis was conducted with DNAMAN 5.1 (Lynnon Corp., Quebec).

The probe for $A d-E X P 1$ was generated using the Random Primed DNA Labeling Kit (Takara, Dalian, China), and Northern blot was performed according to Chen et al. (1999). The region of $A d-E X P 1$ for probe preparation was between EXPSP and EXPAP.

Two oligonucleotide primer sets used for real-time PCR analysis were designed according to the sequences of 3 '-untranslated regions (UTR) of two individual members obtained in the current study using software

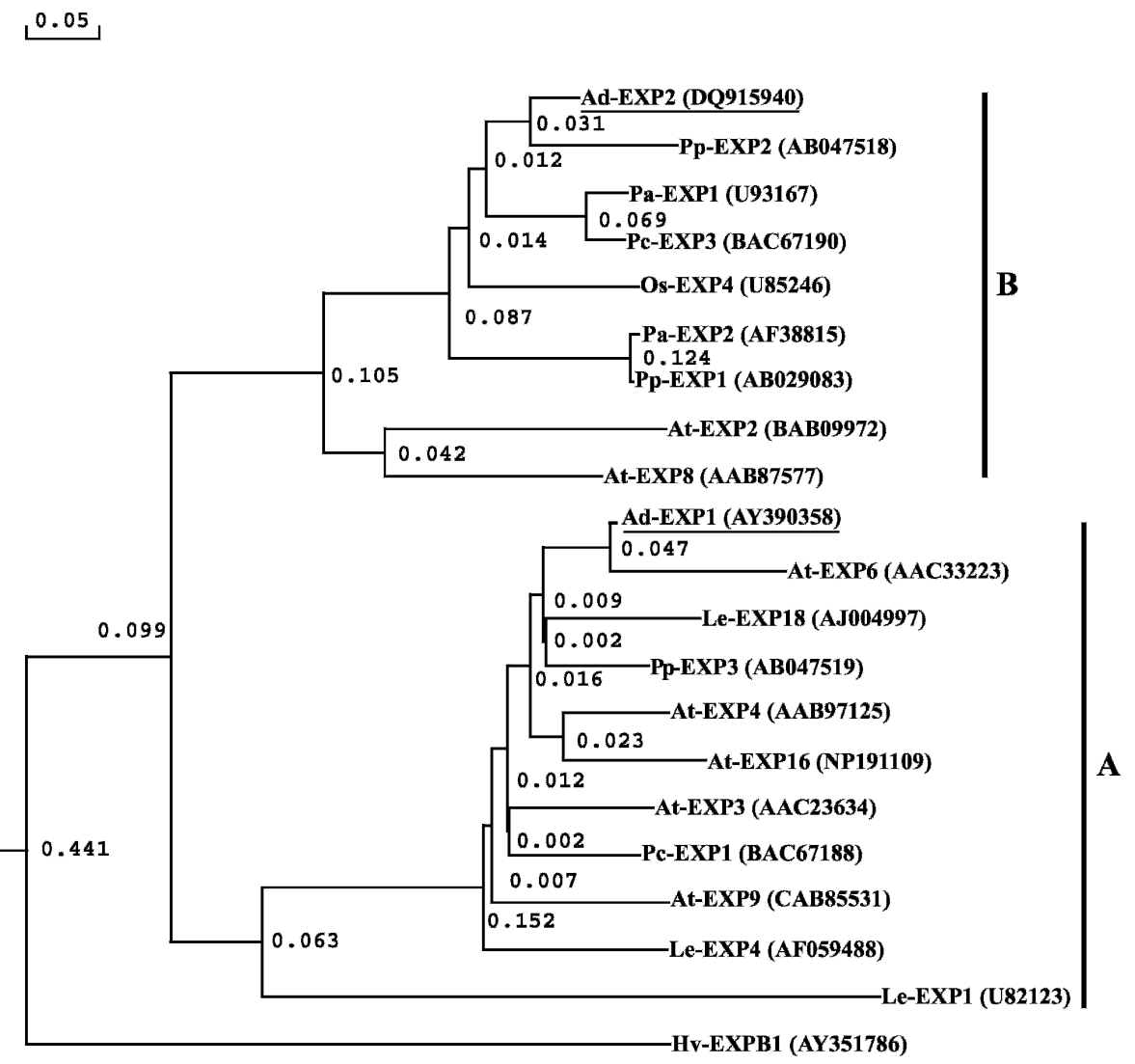

Fig. 2. Phylogenetic tree based on deduced amino acid sequences of Ad-EXP1, Ad-EXP2 and other plant $\alpha$-expansins with Hv-EXPB1 as an outgroup. Phylogenetic distances were indicated between branches. The plants applied are At (Arabidopsis thaliana), Le (Lycopersicon esculentum), $\mathrm{Pa}$ (Prunus armeniaca), Pc (Prunus cerasus), Pp (Prunus persica), Os (Oryza sativa), and Hv (Hordeum vulgare).

ADEXP1SP

Ad-EXP1 TGTTCGTTGGGGAATGTGAAAGGTGAGAGTACTACTTTTTTGACTTGTTTTTGT-TTTGT

Ad-EXP2 TCATTCCAAGGCCCCATTAGGGTGGATAGTTTAGTCAAATTTGTATACTTTTATGCCTGT ADEXP2SP

Ad-EXPI - - TGTTGATTGGGGAGGAGAGGGGT-TGAGTTGTGACATTGTGGCTGAGGCGGCTGCA Ad-EXP2 AAGAGGAGGATTGGATAGTGGAAGTCTCTTAAGTGGCCTTCTAAAGCAGAGGTAGCTGAA

ADEXP1AP

Ad-EXP1 GAA-----AAGAGGCATGT--- AGCCCGCAGC-TCTTCGAAATTTACTAGTGCTATGA Ad-EXP2 GTAGCACCCGAGAGGCCTTTCATAAGATTGTTGTGTCTTCTTCTTCTTCTCTTCTTCTAC

Ad-EXP1 TATAAGTTATA------ -TTTTGATATA----TAAATAATATA-TATATTTGAGAA--- Ad-EXP2 TTTTGGTTTAGGTGCTTTATTGTTGTAGTCTTCAATGATGTAATATAGTTATGCCTTCC ADEXP2AP

\section{Ad-EXP1 -GTTAAAAAAAAAAAAAAA}

Ad-EXP2 TGTCAAAAAAAAAAAAAAA

Fig. 3. Comparison of partial 3' - untranslated region sequences of $A d-E X P 1$ and $A d-E X P 2$ showing framed regions for designed oligonucleotide primers for real-time polymerase chain reaction analysis.

Primer Premier 5.0 (Premier Biosoft Intl., Palo Alto, Calif.). The primers for member $1(A d-E X P 1)$ and member $2(A d-E X P 2)$ were 5' - TCGT T GGGGAA T GT TAAA - 3' (ADEXP1SP, sense), 5'-TCGAAGAGC
TGCGGGCTA-3' (ADEXP1AP, antisense), 5' - T C A T T C C A A G G C C C C A T T - 3' (ADEXP2SP, sense), and 5'-AAGCACCTA AAACCAAAA-3' (ADEXP2AP, antisense) respectively. Real-time PCR was performed 
using the iCycler iQ real-time PCR instrument (BioRad, Hercules, Calif.) in a total volume of $20 \mu \mathrm{L}$ containing $2 \mu \mathrm{L}$ complementary DNAs (cDNAs), $250 \mu \mathrm{m}$ each primer, and $10 \mu \mathrm{L}$ of $2 \times$ SYBR Green PCR Master Mix (BioRad). The predenaturation step was $10 \mathrm{~min}$ at $94{ }^{\circ} \mathrm{C}$, followed by 40 cycles of $94{ }^{\circ} \mathrm{C}$ for $15 \mathrm{~s}$ and $60^{\circ} \mathrm{C}$ for $1 \mathrm{~min}$. Negative controls without template for each primer pair were included in each run. Actin was selected as the internal control to normalize the differences in the amount of templates. The real-time PCR regime for actin was the same as described earlier, except that the primers were 5'-TGCAT GAGCGATCAAGTTTCAAG-3' (ACTSP, sense) and 5'-TGTCCCATGTCTGGTT GATGACT-3' (ACTAP, antisense). Realtime PCR data analysis was performed according to Zhang et al. (2006). Quantification of gene expression was repeated three times from RNA extraction with three replicates in each repeat. The magnitude of expansin expression was expressed as $x$ fold multiples of $18 \mathrm{~S}$ recombinant RNA in Northern blot and of actin in real-time PCR.

\section{Results and Discussion}

Molecular characterization of kiwifruit expansin genes. A fragment of expected size ( $\approx 500 \mathrm{bp}$ ) was amplified by PCR with cDNA reverse transcripted from pulp tissue of ripening kiwifruit as a template and EXPSP and EXPAP as primers. The fragment was cloned into a pUCm-T vector and sequenced. Two different sequences with $497 \mathrm{bp}$ and $491 \mathrm{bp}$ in length, respectively, were obtained, and both were highly homologous to plant EXP gene members. Sequences of $3^{\prime}$ ends of both members, $460 \mathrm{bp}$ and $398 \mathrm{bp}$ in length respectively, were obtained using the RACE kit. In combination, two cDNA fragments, designated as Ad-EXP1 (957 bp, GenBank accession number AY390358) and Ad-EXP2 (889 bp, accession number DQ915940), were obtained with full C-terminal but partial $\mathrm{N}$-terminal protein sequences of 211 and 207 amino acids respectively. The homology between Ad-EXP1 and Ad-EXP2 was 50\% in nucleotide sequence and $74 \%$ in amino acid sequence. Alignment of Ad-EXP1 and Ad-EXP2 amino acid sequences revealed common characteristics of plant EXP gene [e.g., conserved Cys (C) residues, Trp (W) residues, and His-Phe-Asp (HFD) domain (Cosgrove, 2000) as indicated in Fig. 1].

Plant EXPs are encoded by a large superfamily that includes EXP ( $\alpha$-expansin), EXPB ( $\beta$-expansin), EXPL (expansin liked), and EXPR (expansin related) (Cosgrove et al., 2002). Phylogenetic analysis of EXP members suggested that it includes at least four subgroups: A, B, C, and D (GrayMitsumune et al., 2004). In the current study, sequence alignment was done with $20 \mathrm{EXP}$ amino acids sequences from seven plant species and a Hordeum vulgare $\beta$-expansin (Hv-EXPB1) as an outgroup. The results showed that Ad-EXP1 clustered with subgroup A expansin such as At-EXP6, whereas
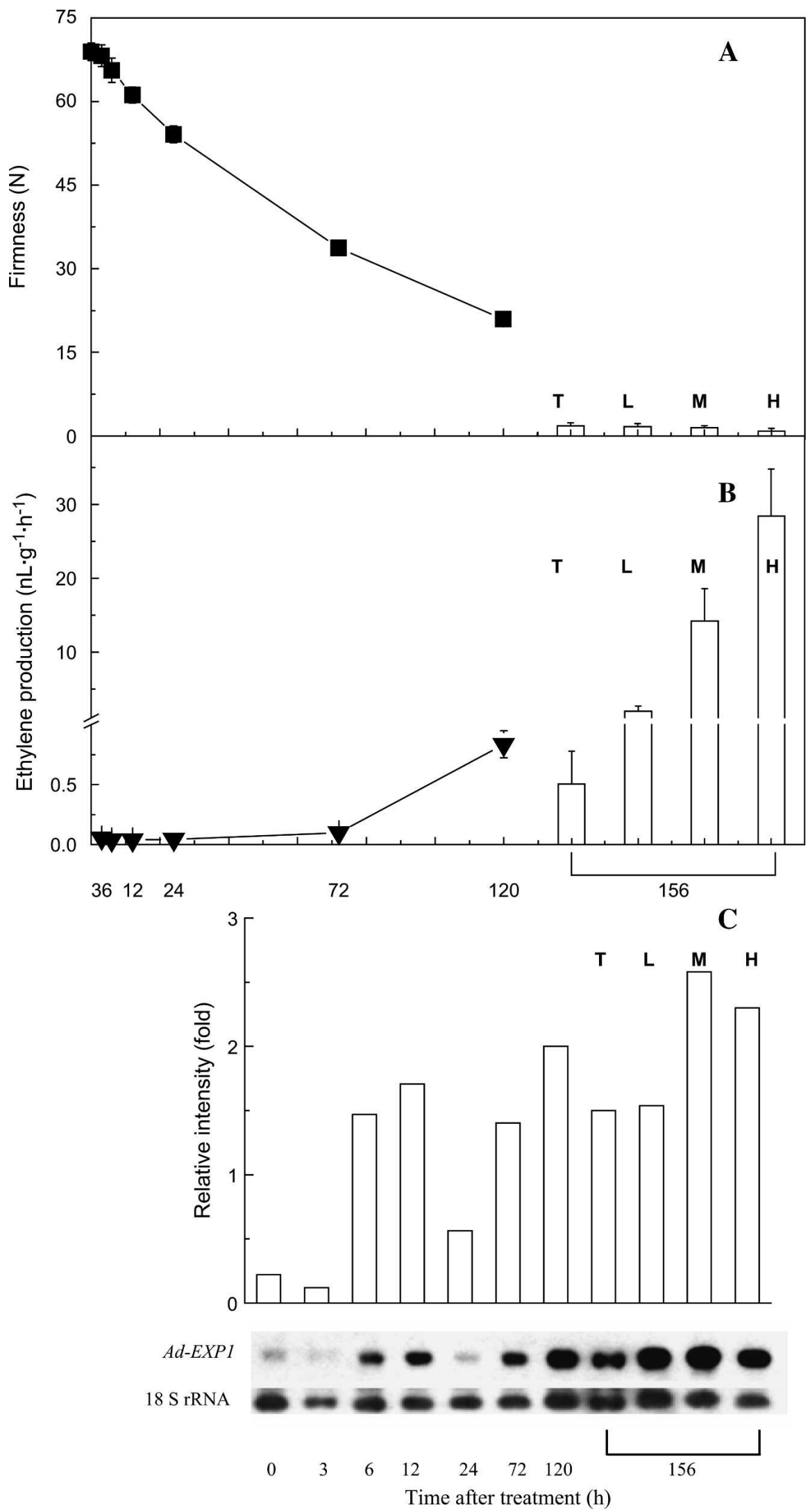

Fig. 4. (A-C) Changes in fruit firmness (A), ethylene production (B), and $A d-E X P 1$ expression (C) in ethylene-treated Actinidia deliciosa fruit. Ad-EXPl expression was expressed as $x$-fold of $18 \mathrm{~S}$ recombinant RNA in Northern blot. T, trace ethylene production rates $\left(<1.0 \mathrm{~nL} \cdot \mathrm{g}^{-1} \cdot \mathrm{h}^{-1}\right) ; \mathrm{L}$, low ethylene production rates $\left(1.0-5.0 \mathrm{~nL} \cdot \mathrm{g}^{-1} \cdot \mathrm{h}^{-1}\right) ; \mathrm{M}$, medium ethylene production rates $\left(5-20 \mathrm{~nL} \cdot \mathrm{g}^{-1} \cdot \mathrm{h}^{-1}\right)$; $\mathrm{H}$, high ethylene production rates $\left(>20 \mathrm{~nL} \cdot \mathrm{g}^{-1} \cdot \mathrm{h}^{-1}\right)$. 
Ad-EXP2 clustered with subgroup B expansin such as At-EXP2 (Link and Cosgrove, 1998) (Fig. 2). Moreover, Fig. 1 showed that Ad-EXP1 and Ad-EXP2 had KNFRV and QF C-terminal amino acid sequences, which are unique to subgroups A and B of the plant EXP gene family (Gray-Mitsumune et al., 2004; Link and Cosgrove, 1998) respectively.

Different EXP members were reported to be involved in various physiological processes such as seed germination, hypocotyl expansion, fruit development, and ripening (Chen et al., 2001). Members of subgroup A, such as $L e-E X P 1$ in tomato, are mainly involved in fruit ripening (Gray-Mitsumune et al., 2004; Rose et al., 1997). Members of subgroup B were mostly related to rapid cell expansion (Gray-Mitsumune et al., 2004; Orford and Timmis, 1998). However, some members of this subgroup (e.g., $P a-E X P 1$ and $P a-E X P 2$ of apricot) were recently found to be expressed in ripening apricot fruit (Gray-Mitsumune et al., 2004; Mbéguié-AMbéguié et al., 2002). In addition, EXP members from different subgroups were also reported to participate in one specific process. For example, both Le-EXP18 of subgroup A and $L e-E X P 2$ of subgroup $\mathrm{B}$ were involved in hypocotyl expansion (Chen et al., 2001). In the current study, both $A d-E X P l$ and $A d-E X P 2$ were expressed in the ripening kiwifruit.
Expression patterns of $A d-E X P 1$ and $A d-$ EXP2 during fruit ripening. Two techniques, Northern blot and real-time PCR, were applied to study the expression patterns of these two EXP members during fruit ripening. For Northern blot, a probe corresponding to the region of $A d-E X P 1$ between EXPSP and EXPAP was prepared. The probe sequence was only $70 \%$ homologous to $\mathrm{Ad}$ EXP2, which successfully prevented a crosshybridization signal from $A d-E X P 2$ (data not shown). For real-time PCR, the primer sets were designed according to the sequence of $3^{\prime}$-UTRs of two individual members (Fig. 3). Polymerase chain reaction amplification produced $142 \mathrm{bp}$ and $198 \mathrm{bp}$ fragments for $\mathrm{Ad}$ EXP1 and $A d-E X P 2$ respectively. The authenticity of fragments was verified by cloning into the pUCm-T vector and then sequencing. Because there were significant sequence differences between two members where the primers were designed, no crossPCR signal was observed (data not shown).

Fruit ripening and softening of kiwifruit were accompanied with rapid loss of fruit firmness and then climacteric ethylene production (Fig. 4A, B), which is consistent with previous studies (Chen et al., 1999; Wang et al., 2000; Zhang et al., 2003). Fruit at $156 \mathrm{~h}$ after ethylene treatment produced ethylene at a nonuniform rate with a range over 150 -fold, although fruit firmness was similarly low
(Fig. 4B). To evaluate the relationship between ethylene production and expression of $A d-E X P 1$, the fruit were separated, according to the ethylene production rate of individual fruit, into trace $\left(\mathrm{T},<1.0 \mathrm{~nL} \cdot \mathrm{g}^{-1} \cdot \mathrm{h}^{-1}\right.$ ethylene), low (L, $1.0-5.0 \mathrm{~nL} \cdot \mathrm{g}^{-1} \cdot \mathrm{h}^{-1}$ ethylene), medium (M, 5-20 nL $\cdot \mathrm{g}^{-1} \cdot \mathrm{h}^{-1}$ ethylene), and high $\left(\mathrm{H},>20 \mathrm{~nL} \cdot \mathrm{g}^{-1} \cdot \mathrm{h}^{-1}\right.$ ethylene $)$ groups. Expression of $A d-E X P 1$ increased by 6.5 -fold within $6 \mathrm{~h}$ after treatment, which was much earlier than the marked dramatic increase in the rate of ethylene production (Fig. 4B, 4C). $A d-E X P 1$ in fruit of $\mathrm{T}, \mathrm{L}, \mathrm{M}$, and $\mathrm{H}$ groups showed similar expression magnitudes (Fig. 4C). Ad-EXP1 responded to ethylene quickly, but the increased rate of ethylene production during the late softening stage, $72 \mathrm{~h}$ after treatment and later, did not result in corresponding increments in the expression of $A d-E X P 1$ (Fig. 4B, C).

Postharvest changes in firmness and ethylene production of ethylene-treated fruit were confirmed in a separate experiment (Fig. 5A, B). Similar to the preceding experiment (Fig. 4B), no significant increase in endogenous ethylene production rate within $24 \mathrm{~h}$ after exogenous ethylene treatment was observed (Fig. 5B). Ethylene production in ethylene-treated fruit was significantly higher than the control at $72 \mathrm{~h}$ and peaked at $216 \mathrm{~h}$ after treatment (Fig. 5B). The expression pattern of $A d-E X P 1$ during fruit softening in
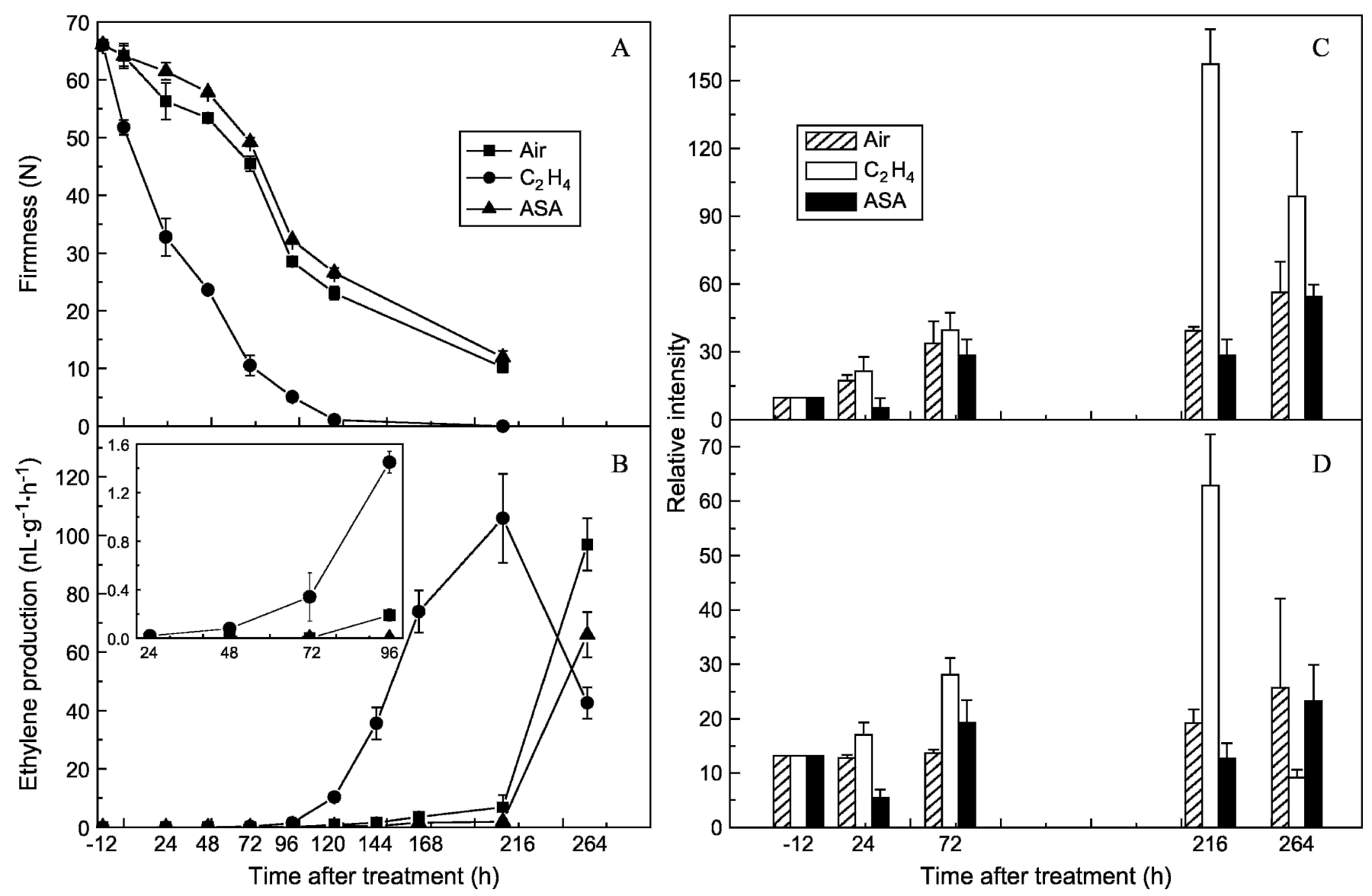

Fig. 5. (A-D) Changes in fruit firmness (A), ethylene production (B), expression of $A d$-EXP1 (C), and expression of $A d$-EXP2 (D) during fruit ripening of Actinidia deliciosa after ethylene or acetylsalicylic acid treatment. The expression magnitude of expansins was expressed as $x$-fold of actin in real-time polymerase chain reaction. 
ethylene-treated fruit, revealed by real-time PCR analysis as shown in Fig. 5C, was consistent with that observed by Northern blot, as shown in Fig. 4C. Expression of $A d$ EXP1 was enhanced several times by ethylene at $216 \mathrm{~h}$ after treatment. The expression pattern of $A d-E X P 2$ was similar to that of $A d$ $E X P 1$, although the expression magnitude was somewhat lower (Fig. 5C, D). Ethylene treatment enhanced expression of EXP members, either ripening or other related developmental process, is supported by previous work (Hayama et al., 2000; Rose et al., 1997).

Salicylic acid and ASA have been reported to delay fruit ripening and inhibit ethylene production in kiwifruit, pear, apple, and banana fruits (Fan et al., 1998; Leslie and Romani, 1988; Zhang et al., 2003). This observation for ASA has been confirmed in the current study. The strongest inhibitory effect of ASA on fruit softening was observed at $24 \mathrm{~h}$ after treatment (Fig. 5A). However, at this sampling time point, the rate of ethylene production was not obviously affected (Fig. 5B). Nonetheless, expression of both $A d$ EXP1 and $A d-E X P 2$ were reduced by more than $50 \%$ (Fig. 5C-D). The data suggest that ASA might exert its effect on retarding fruit softening by inhibiting the expression of EXPs. The interactions between ASA, ethylene, and expression of EXPS merit further investigation.

In conclusion, two expansin cDNAs fragments, $A d-E X P 1$ and $A d-E X P 2$, were isolated from kiwifruit, and their expression patterns were characterized during fruit ripening and after either ethylene or ASA treatment. Phylogenetic analysis showed that these two expansin family members belong to subgroup A and subgroup B respectively. Expression patterns of both members were similar, although $A d-E X P 1$ showed higher messenger RNA (mRNA) abundance than $A d-E X P 2$. Both $A d-E X P 1$ and $A d-E X P 2$ mRNA accumulated during fruit ripening of kiwifruit, and were upregulated by ethylene and downregulated by ASA. The results suggest that both subgroup A and subgroup B expansins are involved in kiwifruit fruit ripening and softening.

\section{Literature Cited}

Bennett, A.B. 2002. Biochemical and genetic determinants of cell wall disassembly in ripening fruit: A general model. HortScience 37:447-450.

Bonghi, C., S. Pagni, R. Vidrih, A. Ramina, and P. Tonutti. 1996. Cell wall hydrolases and amylase in kiwifruit softening. Postharvest Biol. Technol. 9:19-29.

Brummell, D.A., W.J. Howie, C. Ma, and P. Dunsmuir. 2002. Postharvest fruit quality of transgenic tomatoes suppressed in expression of a ripening-related expansin. Postharvest Biol. Technol. 25:209-220.

Chen, F., P. Dahal, and K.J. Bradford. 2001. Two tomato expansin genes show divergent expression and localization in embryos during seed development and germination. Plant Physiol. 127:928-936.
Chen, K.S., F. Li, and S.L. Zhang. 1999. The expression pattern of xyloglucan endotransglycosylase gene in fruit ripening of Actinidia chinensis. Acta Bot. Sin. 41:1231-1234. [In Chinese].

Cosgrove, D.J. 2000. Expansive growth of plant cell walls. Plant Physiol. Biochem. 38:109124.

Cosgrove, D.J., P. Bedinger, and D.M. Durachko. 1997. Group I allergens of grass pollen as cell wall-loosening agents. Proc. Natl. Acad. Sci. USA 94:6559-6564.

Cosgrove, D.J., L.C. Li, H.T. Cho, S. HoffmannBenning, R.C. Moore, and D. Blecker. 2002. The growing world of expansins. Plant Cell Physiol. 43:1436-1444.

Fan, X., J.P. Mattheis, and J.K. Fellman. 1998 Inhibition of apple fruit 1-amino cyclopropane1-carboxylic acid oxidase activity and respiration by acetyl salicylic acid. J. Plant Physiol. 149:469-471.

Fleming, A.J., S. Mcqueen-Mason, T. Mandel, and C. Kuhlemeier. 1997. Induction of leaf primordia by the cell wall protein expansion. Science 276:1415-1418

Gallego, P.P. and I. Zarra. 1997. Changes in cell wall composition and water-soluble polysaccharides during kiwifruit development. Ann. Bot. (Lond.) 79:695-701.

Giovannoni, J.J., D. DellaPenna, A.B. Bennett, and R.L. Fischer. 1989. Expression of a chimeric polygalacturonase gene in transgenic rin (ripening inhibitor) tomato fruit results in polyuronide degradation but not fruit softening. Plant Cell 1:53-63.

Gray-Mitsumune, M., E.J. Mellerowicz, and H. Abe. 2004. Expansins abundant in secondary xylem belong to subgroup A of the $\alpha$-expansin gene family. Plant Physiol. 135:1-13.

Harrison, E.P., S.J. McQueen-Mason, and K. Manning. 2001. Expression of six expansin genes in relation to extension activity in developing strawberry fruit. J. Expt. Bot. 360:1437-1446.

Hayama, H., A. Ito, T. Moriguchi, and Y. Kashimura. 2003. Identification of a new expansin gene closely associated with peach fruit softening. Postharvest Biol. Technol. 291:1-10.

Hayama, H., T. Shimada, T. Haji, A. Ito, Y. Kashimura, and H. Yoshioka. 2000. Molecular cloning of a ripening-related expansin cDNA in peach: Evidence for no relationship between expansin accumulation and change in fruit firmness during storage. J. Plant Physiol. 157:567-573.

Hiwasa, K., J.K.C. Rose, R. Nakano, A. Inaba, and Y. Kubo. 2003. Differential expression of seven $\alpha$-expansin genes during growth and ripening of pear fruit. Physiol. Plant. 117:564-572.

Im, K.H., D.J. Cosgrove, and A.M. Jones. 2000. Subcellular localization of expansin mRNA in xylem cells. Plant Physiol. 123:463-470.

Leslie, C.A. and R.G. Romani. 1988. Inhibition of ethylene biosynthesis by salicylic acid. Plant Physiol. 88:833-837.

Link, B.M. and D.J. Cosgrove. 1998. Acid-growth response and $\alpha$-expansins in suspension cultures of bright yellow 2 tobacco. Plant Physiol. 118:907-916.

Mbéguié-A-Mbéguié, D., B. Gouble, R.M. Gomez, J.M. Audergon, G. Albagnacc, and B. FilsLycaon. 2002. Two expansin cDNAs from Prunus armeniaca expressed during fruit ripening are differently regulated by ethylene. Plant Physiol. Biochem. 40:445-452.

McQueen-Mason, S., D.M. Durachko, and D.J. Cosgrove. 1992. Two endogenous proteins that induce cell wall extension in plants. Plant Cell $4: 1425-1433$

Orford, S.J. and J.N. Timmis. 1998. Specific expression of an expansin gene during elongation of cotton fibres. Biochim. Biophys. Acta 1398:342-346.

Redgwell, R.J. and S.C. Fry. 1993. Xyloglucan endotransglycosylase activity increases during kiwifruit (Actinidia deliciosa) ripening. Plant Physiol. 103:1399-1406.

Redgwell, R.J. and R. Harker. 1995. Softening of kiwifruit discs: Effect of inhibition of galactose loss from cell walls. Phytochemistry 39:13191323.

Rose, J.K.C. and A.B. Bennett. 1999. Cooperative disassembly of the cellulose-xyloglucan network of plant cell walls: Parallels between cell expansin and fruit ripening. Trend Plant Sci. 4:176-183.

Rose, J.K.C., D.J. Cosgrove, P. Albersheim, A.G. Darvill, and A.B. Bennett. 2000. Detection of expansin proteins and activity during tomato fruit ontogeny. Plant Physiol. 123:1583-1592.

Rose, J.K.C., H.H. Lee, and A.B. Bennett. 1997. Expression of a divergent expansin gene is fruit-specific and ripening-regulated. Proc. Natl. Acad. Sci. USA 94:5955-5960.

Ross, C.S., R.J. Redgwell, and E.A. MacRae. 1993. Kiwifruit $\beta$-galactosidase: Isolation and activity against specific fruit cell-wall polysaccharides. Planta 189:499-506.

Sambrook, J. and D. Russell. 2001. Molecular cloning a laboratory manual, p. 1.1-1.170, 3rd ed. Cold Spring Harbor Laboratory Press, N.Y.

Tieman, D.M. and A.K. Handa. 1994. Reduction in pectin methylesterase activity modifies tissue integrity and cation levels in ripening tomato (Lycopersicon esculentum Mill.) fruits. Plant Physiol. 106:429-436.

Tieman, D.M., R.W. Harriman, G. Ramamohan, and A.K. Handa. 1992. An antisense pectin methylesterase gene alters pectin chemistry and soluble solids in tomato fruit. Plant Cell 4:667-679.

Wang, Y., W.J. Lu, J.G. Li, and Y.M. Jiang. 2006a. Differential expression of two expansin genes in developing fruit of cracking-susceptible and resistant litchi cultivars. J. Amer. Soc. Hort. Sci. 131:118-121

Wang, Y., W.J. Lu, J.G. Li, Y.M. Jiang, Y.B. Luo, W.B. Jiang, and D. Joyce. 2006b. Expression of ethylene-related expansin genes in cool-stored ripening banana fruit. Plant Sci. 170:962-967.

Wang, Z.Y., E.A. McRae, M.A. Wright, K.M Bolitho, G.S. Ross, and R.G. Atkinson. 2000 Polygalacturonase gene expression in kiwifruit: Relationship to fruit softening and ethylene production. Plant Mol. Biol. 42:317-328.

Watson, C.F., L. Zheng, and D. DellaPenna. 1994 Reduction of tomato polygalacturonase $\beta$ subunit expression affects pectin solubilization and degradation during fruit ripening. Plant Cell 6:1623-1634.

Xu, C.J., K.S. Chen, B. Zhang, Q.J. Wang, and W.J. Ye. 2004. A study on methods for RNA extraction from citrus tissues. J. Fruit Sci. 21:136-140. [In Chinese].

Zhang, B., K.S. Chen, J. Bowen, A. Allan, R. Espley, S. Karunairetnam, and I. Ferguson. 2006. Differential expression within the LOX gene family in ripening kiwifruit. J. Expt. Bot. 57:3825-3836.

Zhang, Y., K.S. Chen, S.L. Zhang, and I. Ferguson. 2003. The role of salicylic acid in postharvest ripening of kiwifruit. Postharvest Biol. Technol. 28:67-74. 